\title{
BMJ Open Income and housing satisfaction and their association with self-rated health in different life stages. A fixed effects analysis using a German panel study
}

\author{
Anja Knöchelmann (D) , ${ }^{1}$ Nico Seifert (D) , ${ }^{1,2}$ Sebastian Günther, ${ }^{1,3}$ Irene Moor (D) , ${ }^{1}$ \\ Matthias Richter ${ }^{1}$
}

To cite: Knöchelmann A, Seifert N, Günther S, et al. Income and housing satisfaction and their association with self-rated health in different life stages. A fixed effects analysis using a German panel study. BMJ Open 2020;10:e034294. doi:10.1136/ bmjopen-2019-034294

- Prepublication history and additional material for this paper are available online. To view these files, please visit the journal online (http://dx.doi. org/10.1136/bmjopen-2019034294).

AK and NS are joint first authors.

Received 13 September 2019

Revised 05 March 2020

Accepted 09 April 2020

Check for updates

(C) Author(s) (or their employer(s)) 2020. Re-use permitted under CC BY-NC. No commercial re-use. See rights and permissions. Published by BMJ.

${ }^{1}$ Medical Faculty, Institute of Medical Sociology, Martin Luther University Halle Wittenberg,

Halle, Germany

${ }^{2}$ Department of Social Sciences, Sociology, TU Kaiserslautern, Kaiserslautern, Germany

${ }^{3}$ Statistical Office SaxonyAnhalt, Halle, Germany

Correspondence to Dr Anja Knöchelmann; anja.knoechelmann@medizin. uni-halle.de

\section{ABSTRACT}

Objective We aim to investigate the effect of income and housing satisfaction on self-rated health in different life stages.

Design A population-based panel study (German SocioEconomic Panel).

Participants The final sample consisted of 384280 observations from 50004 persons covering the period between 1994 and 2016.

Outcome measures Average marginal effects were calculated based on fixed effects regressions to obtain the effect of changes in income and housing satisfaction on changes in self-rated health for each year of age. Selfrated health was assessed on a 5-point scale, with higher values indicating better health.

Results Changes in income and housing satisfaction showed a small association with changes in self-rated health. The association was stronger for income, where it also varied considerably in different life stages. The average marginal effects for income satisfaction varied between 0.02 and 0.05 in men and 0.02 and 0.04 in women and peaked between the ages of $55-60$. For housing satisfaction, average marginal effects ranged from 0.02 to 0.04 (men) and from 0.02 to 0.03 (women).

Conclusion Higher satisfaction with housing and income was associated with better self-rated health. Therefore, studies on the social determinants of health should not only focus on objective material conditions but also on how individuals perceive and evaluate their situation.

\section{INTRODUCTION}

With regard to health, it is relevant not only what the objective situation of an individual looks like but also how that situation compares to others. Most studies on the association between material conditions and health have relied on objective measures, such as occupational prestige and material deprivation, rather than on the individuals' perspective, ${ }^{12}$ thus concentrating solely on the community level of inequalities. In contrast, the concept of relative deprivation implies that individuals compare themselves to others in certain groups. Reference groups might be (a) a group that the
Strengths and limitations of this study

- Our analysis is based on data from the German Socio-Economic Panel study (GSOEP), a panel survey that is representative of the population in Germany.

- In contrast to previous studies, our results are based on fixed effects models that account for all stable hard-to-observe confounders (e.g. personality), which likely confound the relationship between health and satisfaction.

- However, reverse causation (i.e. health influencing satisfaction) cannot be ruled out.

- Thus, our results are likely unbiased by confounding but potentially biased by reverse causation (i.e. health influencing satisfaction).

individual wants to become a part of (normative reference group), (b) the group that they are already a member of (membership group) or (c) a group that the individual estimates as most contrastive (comparative reference group). ${ }^{3}$ Although different combinations of comparisons may be applied, the focus is often set on a reference group in which all three aspects occur. ${ }^{3}$ Individuals mostly compare themselves to others with similar attributes and the degree of deprivation depends on the difference between what the individuals desire and what they believe other people have and where he or she stands. ${ }^{3-5}$ Previous results have indicated that relative deprivation is associated with mental health, ${ }^{67}$ self-rated health ${ }^{68-10}$ and mortality, ${ }^{11}{ }^{12}$ in part even after adjusting for absolute income..$^{6-911}$ However, it may be problematic that the reference groups, to which the individuals compared themselves, were determined by researchers, although it is not entirely clear to whom these individuals were comparing themselves and whether this applies to the whole study population. ${ }^{3591314}$ Thus, it cannot be regarded as given that it is consistent 
with the actual reference group ${ }^{15}$ or that an individual engages in social comparisons at all. ${ }^{16}$ It is likely that there are a variety of groups that people compare themselves to $^{17}$ and that the intensity of social comparisons differs. ${ }^{18}$ The effects of social comparisons might vary depending on whether the person is identifying or competing with individuals in the reference group. ${ }^{17}$ Other types of comparison, for example, with personal aspirations or desires, ${ }^{15}$ might be even more important than social comparisons for some individuals but have largely been neglected in previous research.

It can be assumed that it is not important to whom individuals are comparing themselves but that it is relevant whether they achieve positive or negative results. ${ }^{1}$ The impact on health can be explained by psychosocial pathways, where social comparisons and experiences of deprivation are associated with insecurity, anger and stress. These feelings can affect health via risky health behaviours (e.g. alcohol consumption, eating habits, smoking) and biological embedding (e.g. blood pressure, allostatic load) ${ }^{19-21}$

This research gap might be closed by using income satisfaction as measure of subjective deprivation, as it includes both the individuals' perception, the evaluation of its material situation and possible resulting psychosocial burdens. According to Miething, ${ }^{15}$ income satisfaction 'can be regarded as the discrepancy between desired income and received income, and the extent to which the received income complies with the individual's expectations and aspirations compared to idealized others and prior income histories.' Measures of income satisfaction allow individuals to prioritise different types of comparisons, in accordance with their personal values and standards. ${ }^{22}$

To the best of our knowledge, only one study has examined the association between income satisfaction and health. In his study, Miething found that the effect of income satisfaction on mortality remained after controlling for income position, educational attainment and employment status, concluding that income itself does not cover the whole spectrum of perceived inequalities. ${ }^{15}$ No study has analysed whether such an association can also be found for other aspects of material situation, such as housing. Housing is an important factor for people's well-being, and according to standard economy theory, an increase in wealth is associated with an increase in the quality of living conditions. ${ }^{23}$ Therefore, a possible interdependency between income and housing satisfaction cannot be ruled out, but evidence on this relationship is scarce.

Furthermore, little is known about whether the association between satisfaction and health varies over different life stages. Studies have shown that income is a strong predictor for health and well-being at different ages. ${ }^{24-26}$ However, it is not clear whether this outcome applies to income satisfaction as well. Potential age differences are implied in the model of sensitive periods, ${ }^{27-30}$ where it is stated that socially relevant periods, such as entry into the job market, parenthood or the transition into retirement, may have an impact on the development of health. It can be assumed that such impacts are attributable to a shift in priorities in different life stages. Our first hypothesis is that this also applies to the association between income or housing satisfaction and subjective health. Our second hypothesis is that income and housing is of varying importance for individuals, and the individuals' perception of housing and income might therefore be variedly associated in different life stages. Therefore, this study aims to examine (a) whether income and housing satisfaction are associated with subjective health and (b) whether this association varies over different life stages.

\section{METHODS}

\section{Study population}

The study is based on data from the German SocioEconomic Panel study (GSOEP, version 33), which is a population-based longitudinal panel survey of private households in Germany. The GSOEP is conducted by the German Institute for Economic Research (DIW Berlin) and provides detailed information about changes and trends in the living conditions of the population living in Germany. Several additional samples have been added since the start of the survey to account for the changing demographic composition of the population. A detailed description of the GSOEP and all subsamples is given elsewhere. ${ }^{31}{ }^{32}$

The sample contains information from persons who were surveyed up to 23 times (observations) during the period between 1994 and 2016. Only the observations in which a person was aged 20-75 years were included in the sample to minimise the risk of bias due to selective mortality in older ages. Persons for whom less than two observations are available and observations for each person in which at least one of the variables contained a missing value in a given survey year were excluded. In total 182238 and 202042 observations from 23702 men and 26302 women were included in the final sample. Descriptive statistics for the analysis sample (including all observations across time) are given in table 1.

\section{Measures}

\section{Health outcome}

Self-rated health (SRH) was used as health outcome, which is strongly associated with morbidity and mortality, ${ }^{33-36}$ thus it is widely seen as a valid measure of a person's general health. The respondents were asked 'How would you describe your current health?' with answers ranging from 1 'very good' to 5 'bad' on a 5-point Likert scale. The original scale was reversed so that higher values indicate better $\mathrm{SRH}$, and the variable was treated as continuous.

\section{Income and housing satisfaction}

Income and housing satisfaction refer to the questions 'How satisfied are you with your household income?' and 'How satisfied are you with your place of housing?'. Both variables were measured on 11-point scales (1 'completely dissatisfied' to 10 'completely satisfied'), which were treated as continuous. Both questions are available in all survey waves between 1994 and 2016 and thus allow a fine-grained 
Table 1 Descriptive statistics of the sample, by gender: German Socio-Economic Panel study 1994-2016

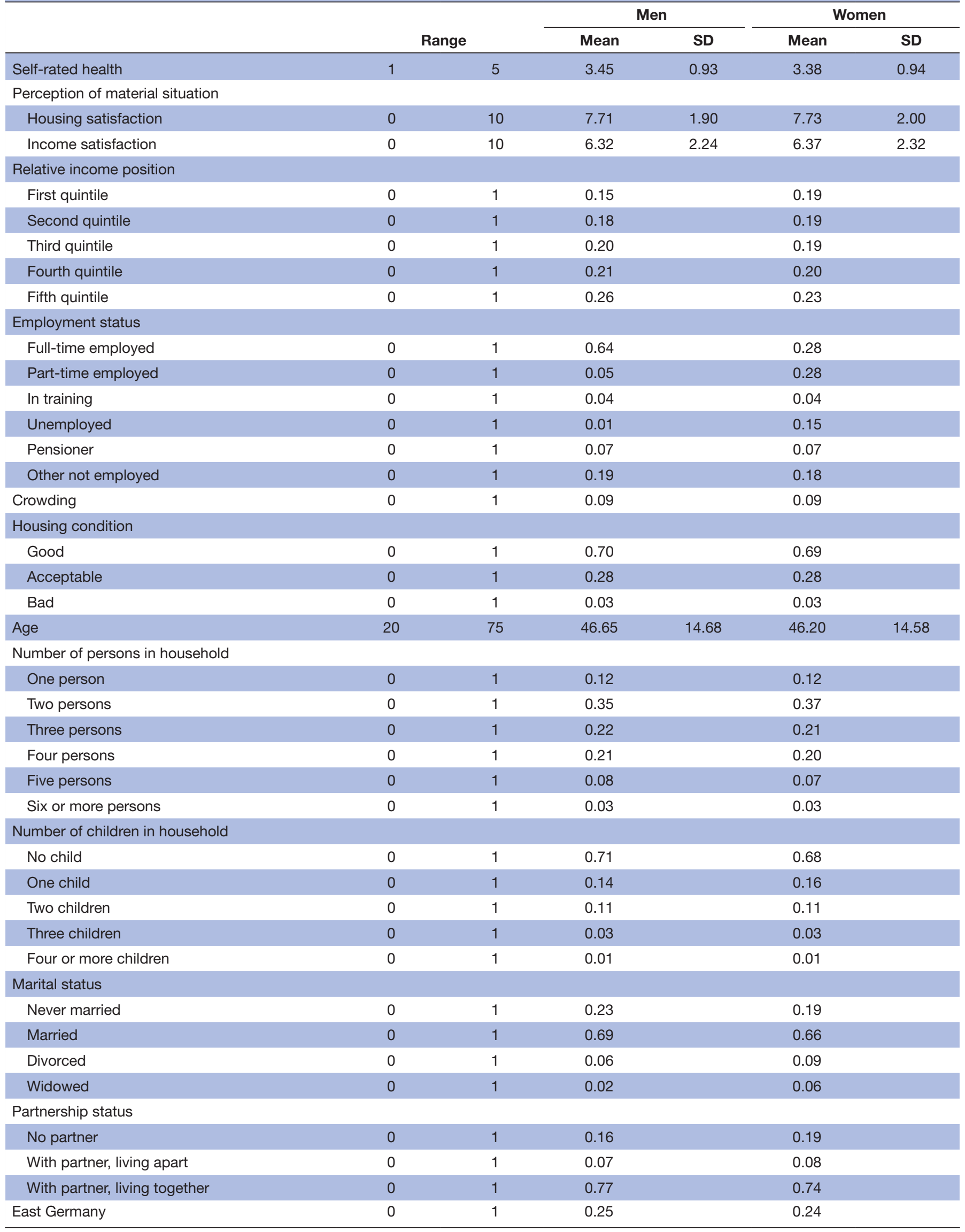




\begin{tabular}{|c|c|c|c|c|c|c|}
\hline \multirow{2}{*}{\multicolumn{2}{|c|}{ Lenath of survey participation }} & & \multicolumn{2}{|c|}{ Men } & \multicolumn{2}{|c|}{ Women } \\
\hline & & Range & Mean & SD & Mean & SD \\
\hline 2 years & 0 & 1 & 0.08 & & 0.09 & \\
\hline 3 years & 0 & 1 & 0.08 & & 0.08 & \\
\hline 6 or more years & 0 & 1 & 0.63 & & 0.62 & \\
\hline Observations & & & 182238 & & 202042 & \\
\hline Persons & & & 23702 & & 26302 & \\
\hline
\end{tabular}

Mean, arithmetic mean.

analysis of life stage patterns. The correlation between income and housing satisfaction was moderate $(r=0.42)$.

\section{Covariates}

All fixed effects models were adjusted for potential timevarying confounders. These included age and age $e^{2}$, which imply a nonlinear relationship between age and health, whereby health declines increasingly faster in older ages. We further adjusted for employment status (full-time employed, part-time employed, in training, unemployed, pensioner and other not employed) and for relative income position, as given by the income quintiles of the equivalised disposable household income, which was calculated based on the modified OECD scale. This scale assigns a weight of 1 to the household head, a weight of .5 to each person aged 14 and over and a weight of .3 to all children below 14 years of age. ${ }^{37}$ The quintiles were calculated for each calendar year using survey weights. They thus reflect the income distribution in the whole population living in Germany in a given year. Additionally, we adjusted for marital status (never married, married, divorced, widowed), partnership status (no partner, with partner/living apart and with partner/ living together), housing conditions (good, acceptable, bad), crowding (less than one room per person available in the household), number of persons and children in the household, region (East vs West Germany), period effects (i.e. specific events at single points in time that affect all individuals in the same way, such as the influence of a financial crisis) by including dummy variables for survey year, and length of survey participation to account for learning effects in the use of the satisfaction scales. ${ }^{38} 39$

\section{Statistical analysis}

To investigate the effect of income and housing satisfaction on SRH and possible age differences in this relationship, linear fixed effects models were estimated separately for men and women.

Because the association between satisfaction and health is likely confounded by third variables, for which no direct measures are available in the data and which thus cannot be easily controlled for, fixed effects models were regarded as the most appropriate model choice for these statistical analyses. ${ }^{40} 41$ These confounders potentially include psychological traits and childhood conditions, which are difficult to measure in surveys. To further mitigate the problem of confounding bias, all time-varying covariates described in the previous section were included in the models. Interactions with age and age $^{2}$ were included in the models to allow the impact of satisfaction to vary non-linearly by age. Additional models allowing an interaction by including a dummy variable for each year of age (with the exception of the age of 20, which was used as the reference category) were estimated as a sensitivity analysis to ensure that the functional form of the interaction effects was correctly specified.

Based on these models, average marginal effects for each year of age were calculated and illustrated in conditional effect plots. To account for the clustering of observations within persons and to make statistical inferences robust to heteroscedasticity, cluster-robust standard errors were computed in all models. All analyses were carried out using Stata V.15.1 (StataCorp, College Station, Texas, USA). ${ }^{42}$

\section{PATIENT AND PUBLIC INVOLVEMENT}

This study does not use patient data. No patients were involved in developing the research question or in determining the outcome measures. Patients were not involved in designing the study. There are no plans to disseminate the results of this study to any participants.

\section{RESULTS}

On average, men and women in the sample were 46.65 and 46.20 years old, respectively, and reported an intermediate level of SRH, with only small gender differences $\left(\overline{\mathrm{x}}_{\mathrm{m}}=3.45, \overline{\mathrm{x}}_{\mathrm{w}}=3.38\right)$ (see table 1$)$. Women and men were generally satisfied with both their income and housing condition, but income satisfaction was lower than housing satisfaction $\left(\overline{\mathrm{x}}_{\mathrm{m}}=6.32, \overline{\mathrm{x}}_{\mathrm{w}}=6.37 ; \overline{\mathrm{x}}_{\mathrm{m}}=7.71, \overline{\mathrm{x}}_{\mathrm{w}}=7.73\right)$.

Figures 1 and 2 show the average marginal effects of within-individual changes in income and housing 

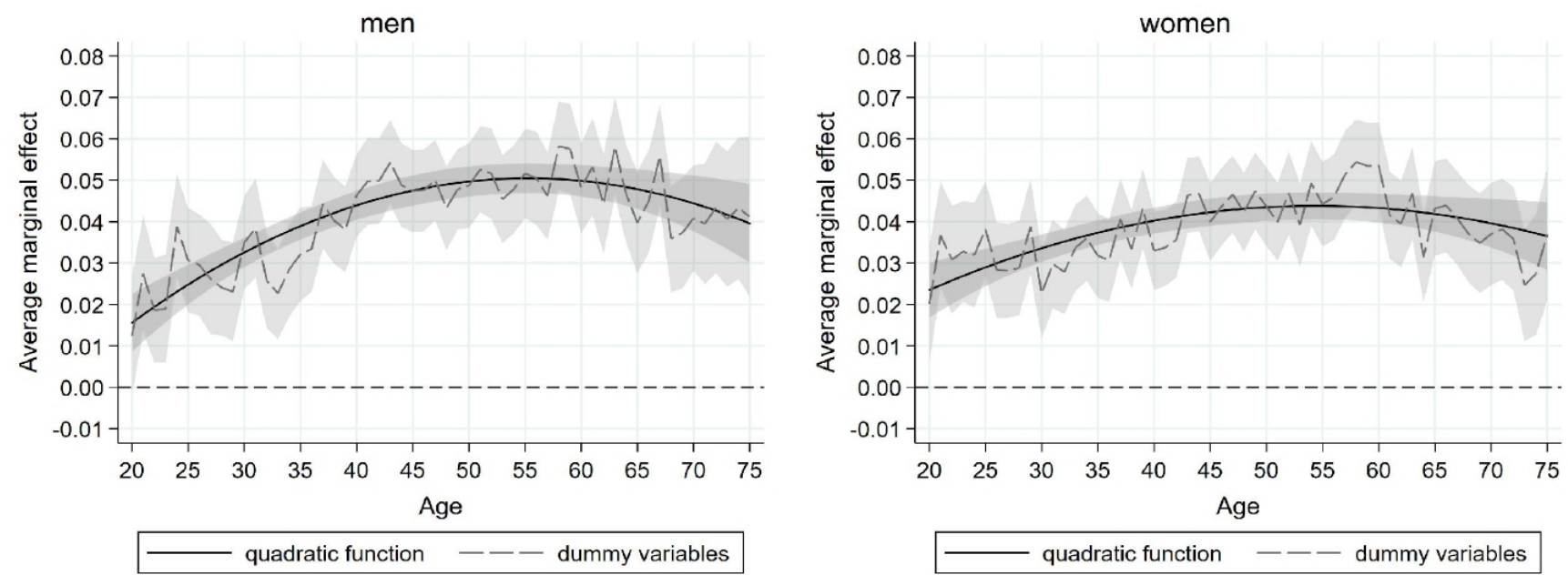

Figure 1 Average marginal effects of changes in income satisfaction on changes in self-rated health: German Socio-Economic Panel study 1994-2016.

satisfaction on changes in SRH from ages 20 to 75 for men and women. Average marginal effects provide information on the degree of change in the dependent variable (SRH) when the independent variable (satisfaction) changes by one scale point. For example, the coefficient for income satisfaction for 20-year-old men indicates an increase in SRH of 0.016 points per 1-point increase in income satisfaction. The following interpretations are based on the models with a quadratic function of the age effect. The tabulated results of all the models can be found as supplementary material (see online supplementary tables 1,2 ).

Figure 1 shows that changes in income satisfaction are positively associated with changes in SRH in all life stages. However, the magnitude of this association varies considerably. It tends to increase as men and women get older, mainly until the mid-to-late $50 \mathrm{~s}$, where the strongest association can be observed. Afterwards, a decrease is noticeable. To illustrate, among young males and females aged 20, a 1-point increase in income satisfaction is associated with a 0.016- and 0.023-point increase in SRH, respectively. These magnitudes for men and women (more than) double to 0.050 and 0.044 at age 55 and then decrease to 0.040 and 0.036 at age 75 (see online supplementary table 1). Hence, while a life course pattern is apparent for both genders, it is slightly more pronounced in men than in women.

Figure 2 shows that changes in housing satisfaction are also positively associated with changes in SRH in all life stages, but far weaker than those for income satisfaction. The association remains small throughout the life course, and for men, a small increase in its magnitude can be observed. Among men, the change in SRH per one scale point change in housing satisfaction amounted to 0.019
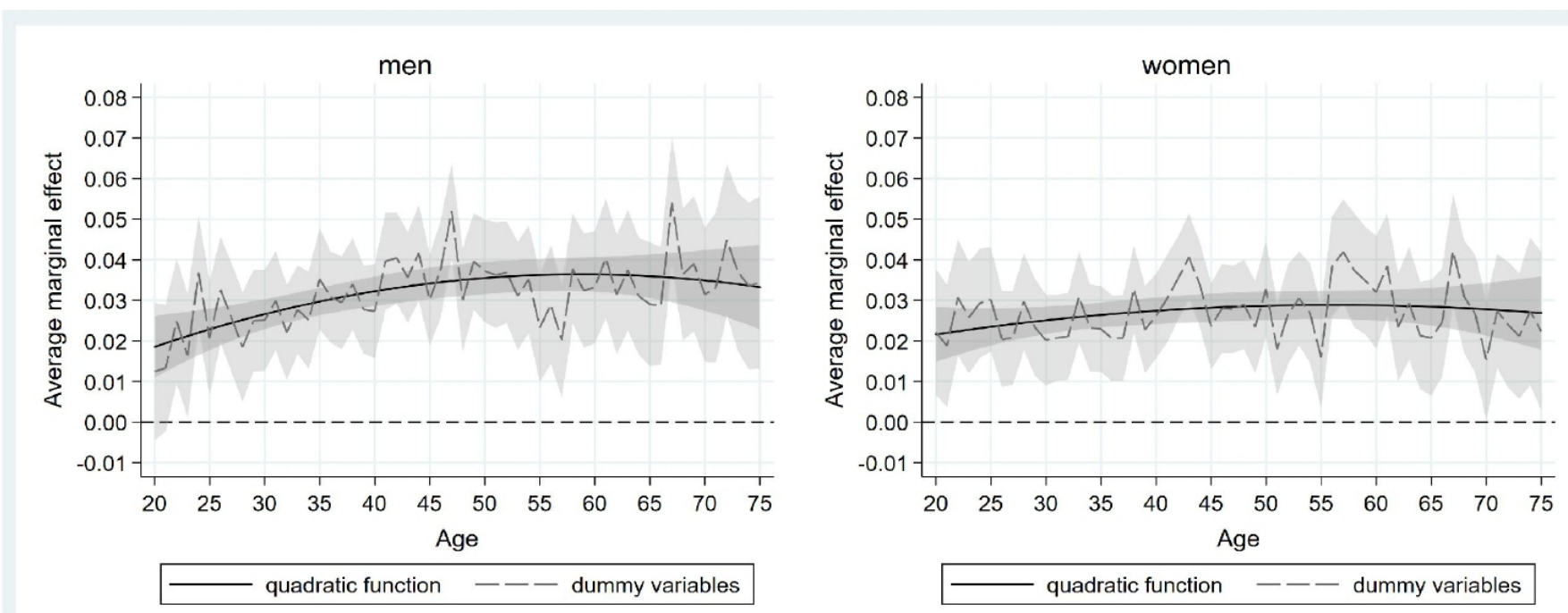

Figure 2 Average marginal effects of changes in housing satisfaction on changes in self-rated health: German SocioEconomic Panel study 1994-2016. 
at age 20, increased to 0.036 at age 55 and remained constant at 0.033 at age 75 . Although the association is again strongest in mid-adulthood, this pattern is clearly less pronounced than that for income satisfaction. Among women, the associations were $0.022,0.029$ and 0.027 at ages 20,55 and 75 , respectively, which were almost identical across all life stages.

\section{DISCUSSION}

The results indicate that changes in income and housing satisfaction are positively, yet rather weakly, associated with changes in SRH. The association is stronger for income than for housing satisfaction. For income satisfaction, the association tended to increase over the life course, peaking at an age of approximately 55-60, followed by a decrease. This pattern was more pronounced for men than women. For housing satisfaction, the association was relatively stable throughout life. The associations cannot be biased by stable characteristics, such as psychological traits and birth cohort, because the used fixed effects models effectively accounted for these factors. It seems likely that these associations reflect an effect of satisfaction with the income and housing situation on SRH. The effects persisted after controlling for income and housing conditions.

Similar findings have been reported for the association between relative deprivation and health outcomes. ${ }^{6-12}$ Studies by Åberg Yngwe et al also showed stronger effects for men than women, ${ }^{10}{ }^{11}$ which is in contrast to other findings on gender differences. ${ }^{89}$ The findings on income satisfaction are comparable to the results by Miething, in which income dissatisfaction was associated with mortality even after taking income into account. ${ }^{15}$ In contrast to our study, he found stronger effects for women than men.

Previous research on relative deprivation and income satisfaction has not examined possible differences between life stages. However, the distribution that was found in our study confirms the results regarding the association between income and health reported by Mackenbach et al, ${ }^{25}$ according to which income inequalities increase until the age of 45-60 and decrease thereafter, remaining at a substantial level. This was shown for SRH, long-term disabilities and limitations in daily activities. Cheung $e t a l^{24}$ similarly reported that the association between income and life satisfaction was stronger for midlife adults than for younger or older adults.

The findings of this study imply that individuals report better health if their housing or income situation is similar to their desired housing or income, which presumably results from comparisons with others or themselves at other ages.

Although the average marginal effects in our study are rather small, the actual health effects might be much stronger than these estimates indicate. The effects apply only to a change of one scale point per year. It is unlikely that a change in income or housing satisfaction occurs only in 1 year over the whole life course. This assumption is supported by an additional analysis (not shown), which indicated that income and housing satisfaction tend to change multiple times even during a short observation period of less than 10 years. Thus, it can be assumed that the rather small effects might accumulate over the life course and add up to a more detrimental effect on health. Additionally, it is unlikely that changes occur only within 1 point on an 11-point scale. Accordingly, the health effects can be quite large for individuals who experience a large drop or rise in satisfaction.

Based on the results, it can be assumed that individuals' income satisfaction is more important than their housing satisfaction for their health. A subjectively sufficient income might have a more pervasive effect on an individual's life than housing satisfaction because income is the key resource for social participation.

This prioritising of income might also explain the observed differences across the life course in terms of changes in priorities in sensitive periods. In our study, the respondents started out in emerging adulthood, where individuals have not yet achieved a mature socioeconomic position. ${ }^{30434}$ This life stage is associated with identity formation ${ }^{43} 44$ and is characterised by the highest rates of residential changes, educational and occupational diversity and instability throughout the life course. ${ }^{43}{ }^{44}$ Becoming an adult is associated with gaining the education and training needed as the foundation for one's future income and professional perspective. ${ }^{44}$ Income or housing satisfaction presumably does not play a large role in the lives of emerging adults, meaning that other factors, such as stable friendships and a supportive network, are more important for their SRH. This life stage is followed by a period of stabilisation, with a more constant residency and little variability in income. Income is increasingly needed as a resource for participating in the community, not only for the individual itself but also for his or her possible dependent family members. Therefore, income satisfaction is increasingly stronger associated with health until middle adulthood because it shows that the individual is capable of being part of the community and that he or she can also provide it for others. The importance of income satisfaction for SRH peaks at the age of 55-60, where two developments meet. First, the individual is presumably at his or her occupational peak and cannot expect further rises in income; thus, he or she starts questioning whether prior aspirations have been met. Second, a shift of priorities is emerging at this time because individuals might be preparing for their transition to retirement. Satisfaction with their current income might imply that they do not have to worry about their retirement, which in return can have a positive impact on their SRH. After this life stage, wealth is more important than income, which explains the decreasing association between income satisfaction and SRH.

The association between income and housing satisfaction and health might also be explained by the idea of psychosocial pathways. According to this idea, feelings of deprivation or dissatisfaction that emerge from social 
comparisons can lead to frustration, insecurity and anger, which in turn can result in risky behaviour and biological embedding, for example higher blood pressure. ${ }^{19-21}$

The GSOEP is a large panel study that is representative of the population in Germany and covers a long period of time. The large sample size enabled us to investigate the association between income and housing satisfaction and SRH at different stages of the life course. By using fixed effects models, we were able to account for all time-constant factors that potentially confound these relationships. These include both observed and unobserved confounders. Hence, our analysis has provided stronger evidence that the associations between income and housing satisfaction and SRH reflects an effect than previous research based on cross-sectional data.

Because fixed effects regressions exploit only the variation within an individual to account for all stable unobserved confounders, effect estimates are based only on those persons for whom a change in income or housing satisfaction is observed in the data. Moreover, fixed effects models are potentially biased by reverse causality. Yet, it seems unlikely that health shocks led to a worse perception of the respondents' income and housing situations, especially because changes in the objective circumstances were controlled for in the analyses. Although health selection cannot be ruled out, it seems plausible that it is more likely that better income and housing satisfaction lead to better SRH. Moreover, in order to be able to account for unobserved stable confounders, we had to treat our measure of SRH as a continuous variable, assuming that the ordinal categories are equally spaced. However, we believe a potential confounding bias poses a higher threat to internal validity.

Although the GSOEP is representative of the German population, generalisation to other countries may be difficult. Individual differences in health are strongly related to income inequality in general, and studies have shown that countries with more unevenly distributed income, as indicated by the Gini coefficient, are more likely to have higher levels of health inequalities. ${ }^{45}{ }^{46}$ Therefore, the presented results are only transferable to countries with a similar income distribution. Furthermore, in Germany, there are a number of measures in place to prevent poverty and homelessness. Thus, even if someone is dissatisfied with one's own housing or income situation, it cannot be assumed that this dissatisfaction results in a lifethreatening situation. However, school trips and cinema visits are not included in the calculation and must also be covered by basic income. Hence, sufficient social participation cannot always be achieved. It can be presumed that the effects vary in countries where the welfare system is organised differently.

We were able to show a positive effect of both income and housing satisfaction on SRH in different life stages, with the strongest associations being found between the ages of 55 and 60. It was shown that these associations are independent of income and housing conditions themselves. Therefore, the subjective evaluations of personal situations need to be assessed to correctly identify less advantaged and vulnerable groups for designing interventions and policymaking. Furthermore, research should also include the subjective dimension of inequality in future analyses on health inequalities.

\section{Twitter Anja Knöchelmann @AnjaKnoechel and Matthias Richter @mrich_er}

Contributors AK led the writing and the revision. NS performed the statistical analyses in collaboration with AK and revised the manuscript. AK and NS designed the study, led the interpretation of the data and wrote the first draft of the article. MR contributed to the conception of the study, supervised the data analyses and provided critical comments on the manuscript. SG assisted with data interpretation. IM assisted with editing and revision of the article. All authors read and approved the final manuscript.

Funding This study is part of the project "Explaining health inequalities in adulthood. A life course perspective using the German Socioeconomic Panel study (GSOEP)", which is funded by the German Research Foundation (DFG), with grant agreement number No. RI2467/2-1.

Competing interests None declared.

Patient and public involvement Patients and/or the public were not involved in the design, or conduct, or reporting, or dissemination plans of this research.

Patient consent for publication Not required.

Ethics approval Because we involved only secondary analysis of anonymised data, ethical approval was not required. The data have been collected in accordance with German data protection laws.

Provenance and peer review Not commissioned; externally peer reviewed.

Data availability statement Data are available upon reasonable request. GSOEP data are available free of charge for scientific use from the German Institute for Economic Research (DIW): https://www.diw.de/en/diw_02.c.222829.en/access_ and_ordering.html

Open access This is an open access article distributed in accordance with the Creative Commons Attribution Non Commercial (CC BY-NC 4.0) license, which permits others to distribute, remix, adapt, build upon this work non-commercially, and license their derivative works on different terms, provided the original work is properly cited, appropriate credit is given, any changes made indicated, and the use is non-commercial. See: http://creativecommons.org/licenses/by-nc/4.0/.

\section{ORCID iDs}

Anja Knöchelmann http://orcid.org/0000-0001-7762-9024

Nico Seifert http://orcid.org/0000-0002-2348-3485

Irene Moor http://orcid.org/0000-0003-3245-5176

\section{REFERENCES}

1 Arber S, Fenn K, Meadows R. Subjective financial well-being, income and health inequalities in mid and later life in Britain. Soc Sci Med 2014;100:12-20.

2 Scambler G. Health inequalities. Sociol Health IIIn 2012;34:130-46.

3 Pedersen AW. Inequality as relative deprivation. Acta Sociol 2004;47:31-49.

4 Runciman WG. Relative deprivation and social justice. London: Routledge, 1966.

5 Lorgelly PK, Lindley J. What is the relationship between income inequality and health? Evidence from the BHPS. Health Econ 2008;17:249-65.

6 Kuo C-T, Chiang T-liang, T-I C. The association between relative deprivation and self-rated health, depressive symptoms, and smoking behavior in Taiwan. Soc Sci Med 2013;89:39-44.

7 Eibner C, Sturn R, Gresenz CR. Does relative deprivation predict the need for mental health services? J Ment Health Policy Econ 2004;7:167-75.

8 Subramanyam M, Kawachi I, Berkman L, et al. Relative deprivation in income and self-rated health in the United States. Soc Sci Med 2009;69:327-34.

9 Kondo N, Kawachi I, Subramanian SV, et al. Do social comparisons explain the association between income inequality and health? Relative deprivation and perceived health among male and female Japanese individuals. Soc Sci Med 2008;67:982-7. 
10 Åberg Yngwe M, Fritzell J, Lundberg O, et al. Exploring relative deprivation: is social comparison a mechanism in the relation between income and health? Soc Sci Med 2003;57:1463-73.

11 Åberg Yngwe M, Kondo N, Hägg S, et al. Relative deprivation and mortality--a longitudinal study in a Swedish population of 4.7 million, 1990-2006. BMC Public Health 2012;12:664.

12 Salti N. Relative deprivation and mortality in South Africa. Soc Sci Med 2010;70:720-8.

13 Mangyo E, Park A, Deprivation R. Relative deprivation and health: which reference groups matter? J Hum Resour 2011;46:459-81.

14 Clark AE, Senik C. Who compares to whom? The anatomy of income comparisons in Europe. Econ J 2010;120:573-94.

15 Miething A. A matter of perception: exploring the role of income satisfaction in the income-mortality relationship in German survey data 1995-2010. Soc Sci Med 2013;99:72-9.

16 Buunk AP, Gibbons FX, Guimond S. Social comparison orientation: a new perspective on those who do and those who don't compare with others. In: Social comparison and social psychology. Cambridge, GBR: Cambridge University Press, 2009: 15-32.

17 Solberg EC, Diener E, Wirtz D, et al. Wanting, having, and satisfaction: examining the role of desire discrepancies in satisfaction with income. J Pers Soc Psychol 2002;83:725-34.

18 Schneider SM, Schupp J. Individual differences in social comparison and its consequences for life satisfaction: introducing a short scale of the lowa-Netherlands comparison orientation measure. Soc Indic Res 2014;115:767-89.

19 Eibner C, Evans WN, et al. Relative deprivation, poor health habits, and mortality. J Hum Resour 2005;XL:591-620.

20 Marmot M, Wilkinson RG. Psychosocial and material pathways in the relation between income and health: a response to Lynch et al. BMJ 2001;322:1233-6.

21 Kondo N. Socioeconomic disparities and health: impacts and pathways. J Epidemiol 2012;22:2-6.

22 Michalos AC. Multiple Discrepancies Theory (MDT). In: Encyclopedia of quality of life and well-being research. Dordrecht: Springer, 2014: 4203-6.

23 Nakazato N, Schimmack U, Oishi S. Effect of changes in living conditions on well-being: a prospective Top-Down Bottom-Up model. Soc Indic Res 2011;100:115-35.

24 Cheung F, Lucas RE. When does money matter most? Examining the association between income and life satisfaction over the life course. Psychol Aging 2015;30:120-35.

25 Mackenbach JP, Meerding WJ, Kunst A. Economic implications of socio-economic inequalities in health in the European Union. Brussels, Belgium: European Commission, 2007.

26 Kriegbaum M, Hougaard Charlotte Ørsted, Andersen I, et al. Life course analysis on income and incident AMI: a Danish register-based cohort study. J Epidemiol Community Health 2019;73:810-6.

27 Bartley M, Blane D, Montgomery S. Socioeconomic determinants of health: health and the life course: why safety nets matter. $B M J$ 1997;314:1194.

28 Burton-Jeangros C, Cullati S, Sacker A, et al. Introduction. In: A life course perspective on health trajectories and transitions. SpringerVerlag, 2015: 1-18.
29 Ben-Shlomo Y, Kuh D. A life course approach to chronic disease epidemiology: conceptual models, empirical challenges and interdisciplinary perspectives. Int J Epidemiol 2002;31:285-93.

30 Halfon N, Hochstein M. Life course health development: an integrated framework for developing health, policy, and research. Milbank Q 2002;80:433-79.

31 Goebel J, Grabka MM, Liebig S, et al. The German socio-economic Panel (SOEP). Jahrbücher für Nationalökonomie und Statistik 2018:239:jbnst-2018-0022.

32 Wagner GG, Göbel J, Krause P, et al. Das Sozio-oekonomische Panel (SOEP): Multidisziplinäres Haushaltspanel und Kohortenstudie für Deutschland - Eine Einführung (für neue Datennutzer) MIT einem Ausblick (für erfahrene Anwender). AStA Wirtsch Sozialstat Arch 2008;2:301-28

33 Latham K, Peek CW. Self-rated health and morbidity onset among late midlife U.S. adults. J Gerontol B Psychol Sci Soc Sci 2013;68:107-16.

34 DeSalvo KB, Bloser N, Reynolds K, et al. Mortality prediction with a single general self-rated health question. A meta-analysis. $J$ Gen Intern Med 2006;21:267-75.

35 Singh-Manoux A, Martikainen P, Ferrie J, et al. What does self rated health measure? Results from the British Whitehall II and French Gazel cohort studies. J Epidemiol Community Health 2006;60:364-72.

36 Idler EL, Benyamini Y. Self-rated health and mortality: a review of twenty-seven community studies. $J$ Health Soc Behav 1997;38:21-37.

37 OECD. What are equivalence scales? Paris: Organisation for economic co-operation and development (OECD) - Directorate for Employment, Labour and Social Affairs, 2011.

38 Wunder C, Wiencierz A, Schwarze J, et al. Well-Being over the life span: semiparametric evidence from British and German longitudinal data. Rev Econ Stat 2013;95:154-67.

39 Ehrhardt JJ, Saris WE, Veenhoven R. Stability of life-satisfaction over time. J Happiness Stud 2000;1:177-205.

40 Gunasekara FI, Richardson K, Carter K, et al. Fixed effects analysis of repeated measures data. Int J Epidemiol 2014;43:264-9.

41 Leyland AH. No quick fix: understanding the difference between fixed and random effect models. J Epidemiol Community Health 2010;64:1027-8.

42 StataCorp. Stata statistical software: release 15. College Station, TX: StataCorp LP, 2017.

43 Arnett JJ, Žukauskienė R, Sugimura K. The new life stage of emerging adulthood at ages 18-29 years: implications for mental health. Lancet Psychiatry 2014;1:569-76.

44 Arnett JJ. Emerging adulthood. A theory of development from the late teens through the twenties. Am Psychol 2000;55:469-80.

45 Pickett KE, Wilkinson RG. Income inequality and health: a causal review. Soc Sci Med 2015;128:316-26.

46 Lynch JW, Kaplan GA. Socioeconomic position, in: Berkman Lf, Kawachi I, EDS. Social epidemiology. New York: Oxford University Press 2000:13-35. 